\title{
Roll forming of a high strength AA7075 aluminum tube
}

\author{
Timon Suckow ${ }^{1}\left[\right.$ ] Julius Schroeder ${ }^{1} \cdot$ Peter Groche $^{1} \mathbb{D}$
}

Received: 21 January 2021 / Accepted: 9 March 2021 / Published online: 18 March 2021

(c) The Author(s) 2021

\begin{abstract}
The presented paper provides a modelling strategy for roll forming of a high strength AA7075 aluminum tube. Roll forming allows the cost-effective production of large quantities of long profiles. Forming of high strength aluminum brings challenges like high springback and poor formability due to the low Young's modulus, low ductility and high yield strength. Forming processes with high strength aluminum, such as the AA7075 alloy, therefore require a detailed process design. Three different forming strategies, one double radius strategy and two W-forming strategies are discussed in the paper. The paper addresses the question whether common roll forming strategies are appropriate for the challenge of roll forming of a high strength aluminum tube. For this purpose, different forming strategies are investigated numerically regarding buckling, longitudinal strain distribution and final geometry. While geometry is quite the same for all strategies, buckling and strain distribution differ with every strategy. The result of the numerical investigation is an open tube that can be welded into a closed tube in a subsequent step. Finally, roll forming experiments are conducted and compared with the numerical results.
\end{abstract}

Keywords Roll forming $\cdot$ Aluminum $\cdot$ High strength $\cdot 7075 \cdot$ Tube $\cdot$ Springback

\section{Introduction}

Current research in production technology focuses primarily on increasing resource efficiency and thus follows the approach of fundamental sustainability of processes and products. High strength aluminum alloys (e.g. AA7075) are commonly used in aerospace applications in spite of their high cost of about $5 € / \mathrm{kg}$ and poor formability [1]. Due to ambitious legal requirements, such as the $\mathrm{CO}_{2}$ target in automotive engineering, new lightweight construction concepts are still needed [2]. An excellent basis is offered by the production of high strength AA7075 thin walled tubes as semi-finished products by roll forming. These can be further processed in subsequent customized processes such as welding, stamping, cutting or rotary swaging.

According to DIN 8586, roll forming is a bending technology with rotating tool motion to produce open and closed profiles [3]. Several pairs of forming rolls are aligned one behind the other for the forming process. The friction between the rotating forming rolls and the sheet metal

Timon Suckow

suckow@ptu.tu-darmstadt.de

1 Institute for Production Engineering and Forming Machines, Technical University Darmstadt, 64287 Darmstadt, Germany causes a forward movement of the sheet. Simultaneously the sheet is formed in and between the stations. For the production of large quantities, roll forming is a cost-effective manufacturing process, compared to tube extrusion or tube drawing. Roll forming can also be competitive for smaller quantities, if the number of forming passes is small enough [4]. The incremental nature of the roll forming process also allows forming of high strength materials, such as ultra high strength steel (UHSS) [5].

During roll forming there is a limit for the amount of deformation regarding buckling limit strain (BLS), which can be reached in one forming station [6]. Abeyrathna [5], Park [7] and Bui [8] showed that longitudinal strain has a major impact on product defects, such as bow or buckling. The maximum longitudinal strain occurs in the area of the band edge. Plastic elongation in the roll gap between the forming rolls followed by compression when the sheet leaves the forming rolls leads to buckling. Figure 1 illustrates the elongation, followed by compression when forming a tube. To prevent buckling, the maximum longitudinal strain must be low. Once buckling takes place, welding of the formed tube becomes very difficult or even impossible [9]. Parameters with a large influence on buckling are the stiffness of the sheet and the yield strength of the material. According to Halmos [10], elongation of the band edge 


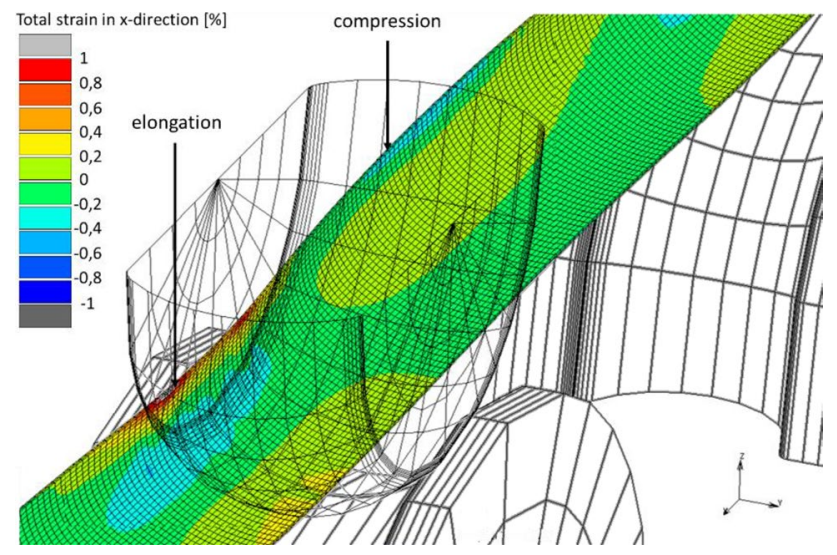

Fig. 1 Elongation of the band edge, followed by compression in the roll forming process

depends on the flange height and inter-station distance $l_{d}$. High bending angles of a single forming station $\Theta_{p}$ and a small inter-station distance $l_{d}$ lead to large elongation of the band edge and thus to buckling. For circular sections (e.g. tube), the BLS is 5-10 times higher than the BLS for a U-profile [6].

Groche et al. [11], Park et al. [7], Zou et al. [12] and Lee et al. [13] showed that roll forming of high strength materials and especially of high strength aluminum brings challenges compared to commonly roll formed steel grades. High strength leads to high springback and thus to less dimensional accuracy in the processed part. Parameters, which have an influence on springback are shown in Table 1. Difficulties regarding aluminum include early fracture due to low ductility, higher springback and redundant deformation. This requires a well-designed forming strategy in order to get the lowest possible springback and buckling in the roll forming process and the best quality of the processed part. In contrast, aluminum shows a goodnatured behavior with regard to buckling due to a higher value of BLS compared to steel [14].

Table 1 Parameters with an influence on springback during roll forming [15]

\begin{tabular}{llllll}
\hline Parameter & $\begin{array}{l}\text { Yield } \\
\text { strength } \uparrow\end{array}$ & $\begin{array}{l}\text { Young's } \\
\text { modu- } \\
\text { lus } \uparrow\end{array}$ & $\begin{array}{l}\text { Bending } \\
\text { radius } \uparrow\end{array}$ & $\begin{array}{l}\text { Sheet } \\
\text { thick- } \\
\text { ness } \uparrow\end{array}$ & $\begin{array}{l}\text { Forming } \\
\text { strategy }\end{array}$ \\
\hline $\begin{array}{l}\text { Amount } \\
\text { of } \\
\text { spring- } \\
\text { back }\end{array}$ & $\uparrow$ & $\downarrow$ & $\uparrow$ & $\downarrow$ & $\begin{array}{c}\text { To be } \\
\text { investi- } \\
\text { gated }\end{array}$ \\
\hline
\end{tabular}

\section{State of the art roll forming of tubes}

Roll forming of tubes has been numerically investigated in the past. Wen and Pick [16] as well as Salmani et al. [17] investigated edge buckling when roll forming circular tube sections. Breitenbach [15] and [18] compared different forming strategies regarding forming behavior. Different forming strategies for roll forming of tubes, which have been investigated, are illustrated in Fig. 2.

The single radius-forming strategy has the advantage to form tubes with different sheet thickness on the same tool. A flower pattern with constant bending radius over the entire cross-section of the sheet is characteristic for the single radius-forming. For high-strength materials, the single radius-forming strategy is not applicable due to high springback caused by the high elastic bending content $[10,18]$.

The double radius- and $\mathrm{W}$-forming strategies are appropriate for high strength steels. For both strategies, two radii are combined in each pass, whereby the radius in the edge area is equal to the end radius already in the first pass of the process [18]. In contrast to double radius forming, a negative bending is initially introduced in the middle section in the $\mathrm{W}$-forming process. The main advantage of this strategy is that the final radius can be formed into the band edge area at the first pass of the process [18]. Another approach is described by Jiang et al. [19] with a cage roll forming mill for the production of electric resistance welded pipes.

The height displacement of the profile is called "up-hill" or "down-hill". During the down-hill strategy, the profile is lowered step by step in each pass. The use of a down-hill forming strategy can reduce plastic elongation in the band edge and thus the number of forming stations [10]. Based on the fundamental differences in roll forming between aluminum and steel, this publication addresses the question if one of the strategies suits for forming a tube of the highstrength aluminum alloy AA7075.

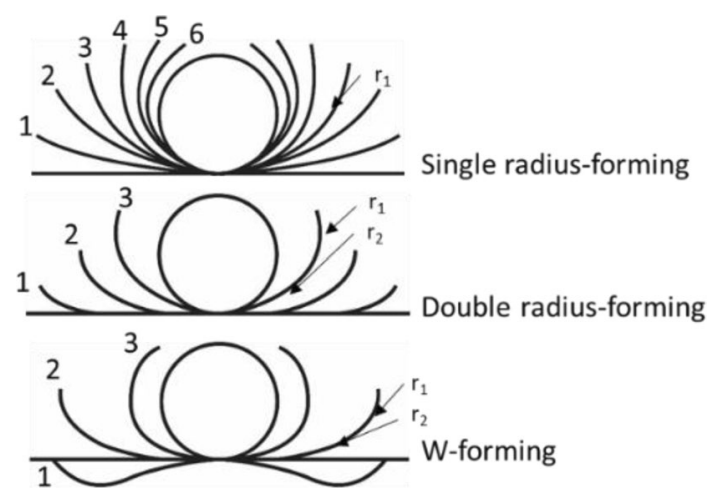

Fig. 2 Flower patterns of different forming strategies for roll forming of a tube [According to 15] 


\section{FE-Simulation of the roll forming process}

The roll forming tools are designed by numerical simulation of the process. The target geometry is a tube with an outer diameter of $d=54.98 \mathrm{~mm}\left(r_{o}=27,49 \mathrm{~mm} / r_{i}=25,99 \mathrm{~mm}\right)$ and a wall thickness of $s_{0}=1.5 \mathrm{~mm}$. An AA7075-T6 aluminum alloy is used for the roll forming process. Table 2 shows the mechanical properties of the alloy.

\subsection{FE-Model for the roll forming process}

In this investigation, the model serves to predict the final geometry of the tube in the process design phase, especially with regard to buckling. According to Volk et al. [20], accuracy and precision of a model are important for process design, while model execution time or flexibility are of much less importance. An accurate model must deliver an output close to the output of the real process [21]. In the numerical investigations, the roll forming process is designed with the Software UBECO Profil and the FE-Software MSC Marc Mentat 2012. The tools designed in UBECO Profil are manually imported into Marc Mentat using a python script. The flow curve for the numerical simulation shown in Fig. 6 was obtained by tensile tests according to DIN EN ISO 6892:1 [22] on a Zwick Roell 100 tensile testing machine and is based on the Ludwik-Holomon equation. Therefore, tensile specimen with a width of $12.5 \mathrm{~mm}$ were milled from the aluminum coil. An isotropic hardening model is implemented in the simulation (Fig. 3).

Damm [23], Bui [8], Groche [24] and Mueller [25, 26] showed that friction has not a huge influence on the results in roll forming simulations in terms of profile geometry. Thus, friction is neglected in the FE-model to reduce computing time. The simulation uses a node-to-segment contact algorithm. In the FE-model, the roll forming stand and the roll forming tools are rigid due to insignificant influence on the geometrical outputs of the simulation, such as strains or geometry [26]. Only the evaluation of load conditions (force, torque) would require compliant tools [24].

The aim in the selection of the meshing strategy is to compromise between result accuracy of the simulation and computation efficiency. Moneke [27] and Goertan [28] use an element size of $5 \mathrm{~mm}$ in sheet length direction in their models for the simulation of a roll forming process. At least two element layers in direction of the sheet thickness are necessary to represent the different stress states across the sheet thickness [29]. A convergence analysis was performed with a finer mesh $(2.5 \mathrm{~mm} \times 2 \mathrm{~mm} \times 0.375 \mathrm{~mm})$ successfully to verify the mesh size $(5 \mathrm{~mm} \times 2 \mathrm{~mm} \times 0.75 \mathrm{~mm})$ by evaluation of the final geometry. Computing time (1 Core-Intel i7-6700 CPU) increases from $90 \mathrm{~h}$ for the standard mesh to $230 \mathrm{~h}$ for the fine mesh. To emulate the calibration process with the occurring tangential and radial compressive stresses with sufficient accuracy, the model is based on solid 8 -node elements. Figure 4 shows the simulation setup of the half-symmetric roll forming process and the key boundary conditions.

\subsubsection{Initial situation}

In the initial design stage for finding an appropriate forming strategy, the focus is on achieving the target geometry and avoid plastic buckling by keeping longitudinal strain low in the band edge. The most economical way to design a roll forming process is to keep longitudinal strain just below the BLS. For design of the roll forming strategies, the cross section is divided into two parts (Fig. 5).

Figure 6 shows the procedure for designing the roll forming process. The first step is the definition of the target geometry, followed by the design of the flower pattern with UBECO Profil. The profile stress analysis (PSA) in UBECO Profil is based on a geometric model of the forming section and gives a fast overview of the longitudinal stress (strain) distribution during the forming process. When the strain is below the critical limit, the tools

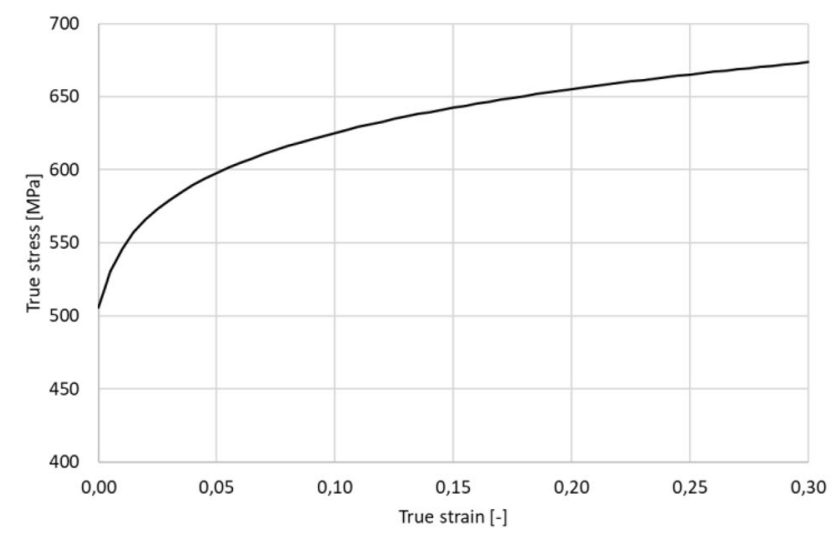

Fig. 3 Flowcurve of the AA7075 aluminum alloy

Table 2 Mechanical properties of the AA7075 alloy

\begin{tabular}{|c|c|c|c|c|c|c|}
\hline $\begin{array}{l}\text { Yield strength } \mathrm{R}_{\mathrm{p} 0,2} \\
\text { (MPa) }\end{array}$ & $\begin{array}{l}\text { Tensile strength } \mathrm{R}_{\mathrm{m}} \\
\text { (MPa) }\end{array}$ & $\begin{array}{l}\text { Young's Modulus E } \\
\text { (GPa) }\end{array}$ & $\begin{array}{l}\text { Elongation at frac- } \\
\text { ture A }(\%)\end{array}$ & Density $\rho\left(\mathrm{g} / \mathrm{cm}^{3}\right)$ & $\begin{array}{l}\text { Sheet thickness } \mathrm{s}_{0} \\
(\mathrm{~mm})\end{array}$ & $\begin{array}{l}\text { Sheet width } b_{0} \\
(\mathrm{~mm})\end{array}$ \\
\hline 505 & 567 & 72 & 11 & 2.81 & 1.5 & 168 \\
\hline
\end{tabular}


Fig. 4 Setup of FE-model

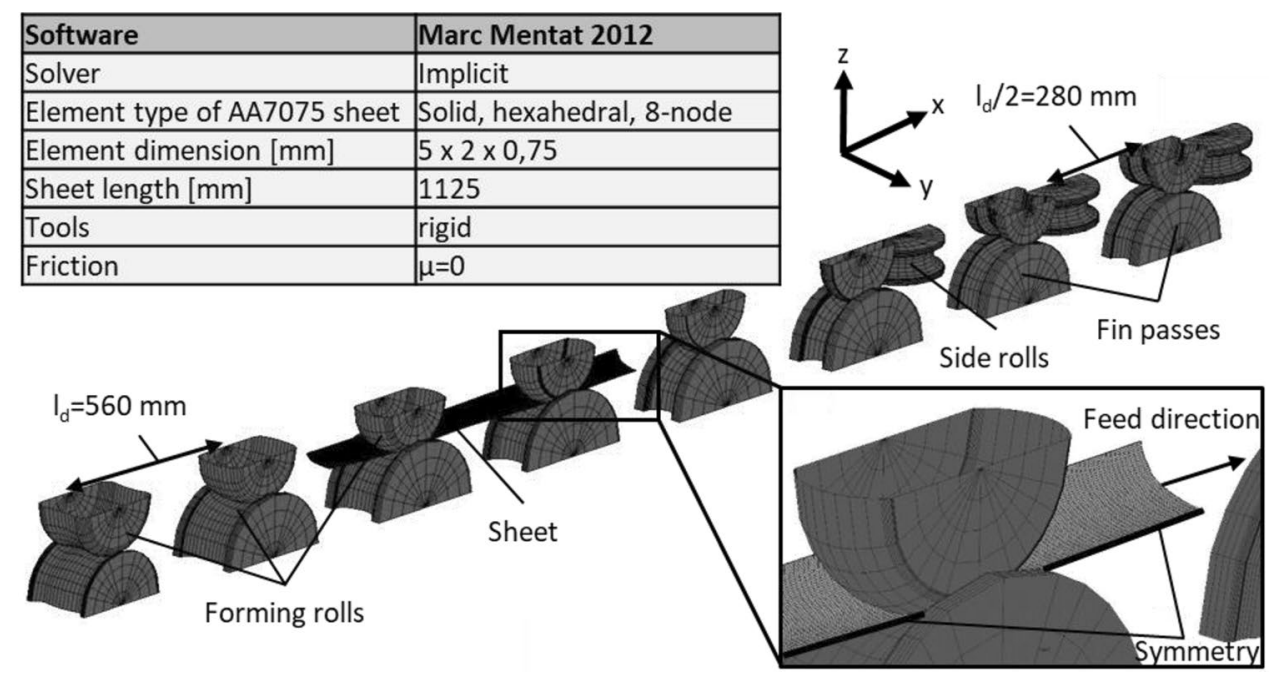

Fig. 5 Divided cross section of the tube-schematic illustration of the double radius forming strategy

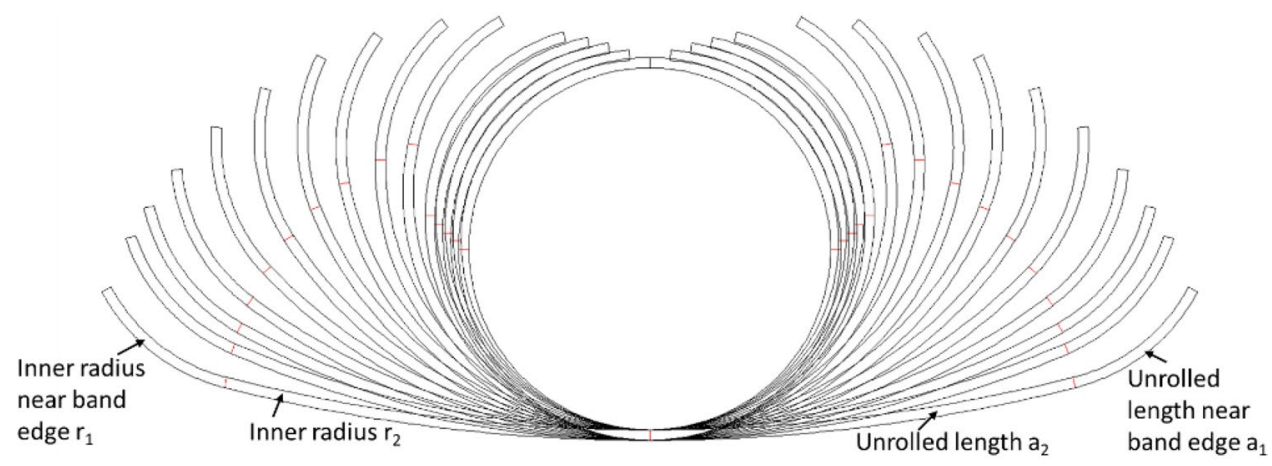

are transferred to the FE-model. The results of the FEanalysis are more accurate than the PSA and provide the stresses and springback during the entire forming process. When buckling or bow occurs, another forming strategy is required. In the last step, the focus is on increasing process efficiency by reducing the amount of passes.

The first forming strategy suggested automatically by UBECO Profil after defining the target geometry is a double radius-forming strategy and has 27 passes in total. Based on tube forming sequences in literature [15, $16]$, the number of passes is reduced to 14 passes by skipping every second pass, in order to increase process efficiency. After the reduction to 14 passes, the edge strain is still below the critical limit in every stage of the process according to the PSA. The approach for the first forming strategy is to form the tube in uniform increments and to keep the longitudinal strain low in the band edge. The further approach is to calculate the stresses of the formed tube to arrive at the number of passes required. Forming strategy $2 \mathrm{R}$ is the first strategy numerically investigated by the FE-software Marc Mentat.

\subsubsection{Double radius forming}

The aim of the investigation of forming strategy $2 \mathrm{R}$ is to provide a basis for improvement by designing further forming strategies. Forming strategy $2 \mathrm{R}$ has 14 passes in total including two fin passes, to keep the strategy comparable to the first double radius-forming strategy. In order to achieve a smooth forming behavior of the band edge, the radius in the band edge area is $r_{1}=30 \mathrm{~mm}$ in pass 1 and reduced to the final radius $r_{1}=26 \mathrm{~mm}$ until pass 5 . From pass 5 the target radius is formed $\left(r_{1}=r_{i}\right)$ in the band edge. Radius $r_{2}$ in the middle section of the sheet is reduced in every path to achieve uniform forming increments. For the first strategy $2 R$ investigated, this is the approach of the design for the flower pattern. The unrolled length in the band edge area is $a_{1}=22.3 \mathrm{~mm}$ in the first two passes, as suggested by UBECO Profil, and increases in every pass. The top rolls of the fin passes induce a circumferential compression on the tube to create the target geometry and to reduce springback. In the last pass, the final geometry is formed within each forming strategy. 


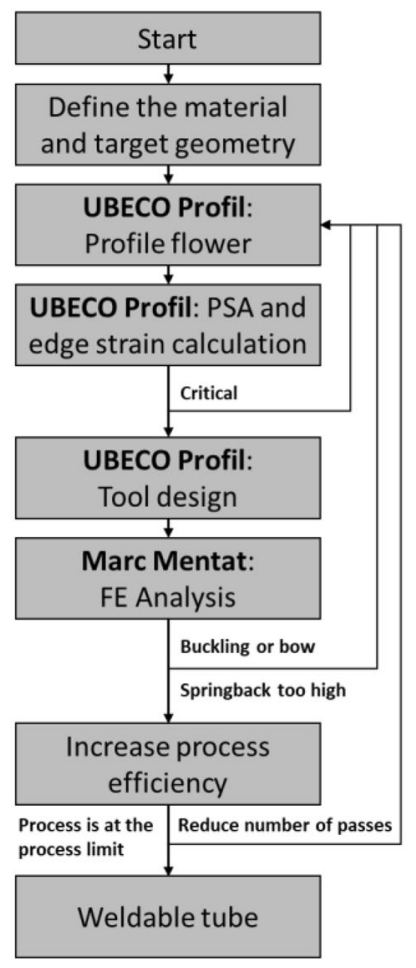

Fig. 6 Iterative design process for the development of roll forming tools

\subsubsection{W-forming strategies}

Forming strategy $\mathrm{W} 1$ is quite similar to forming strategy $2 \mathrm{R}$, except for the $\mathrm{W}$-forming pass at the begin of the process. Furthermore, a breakdown pass replaces the side rolls in pass two. The goal of the investigation of forming strategy $\mathrm{W} 1$ is to see the influence of the $\mathrm{W}$-forming stage in the first stage on the forming behavior and buckling.

The next step in the optimization process is to reduce the number of passes and to increase efficiency of the process. In general, the approach is to keep the longitudinal strain in the band edge as equal as possible in every pass and simultaneously avoiding high peaks of longitudinal strain. Within the second $\mathrm{W}$-forming strategy $\mathrm{W} 2$ the end radius $r_{1}=r_{i}$ is bended in the first pass already. In addition, the unrolled length near the band edge is $a_{1}=34.4 \mathrm{~mm}$ from the first pass, which is longer compared to strategy $2 \mathrm{R}$ and $\mathrm{W} 1$. The idea is to create a larger zone of extensive bending from the begin of the forming process to reduce springback and increase efficiency. Another improvement is the implementation of the downhill-strategy.

\subsubsection{Summary of the strategies}

Figure 7 and Table 3 show a summary of the forming strategies, investigated in this paper. The forming strategies are defined by means of the software UBECO Profil. The last five passes have the same geometry within each forming strategy, to keep the focus on the tube forming process and minimize the impact of the fin passes on the results.

\subsection{Discussion of the FE-results}

For comparison of the forming strategies the longitudinal strain in the band edge is evaluated for each forming strategy. Figure 8 shows the node for evaluating the longitudinal strain and the strain distribution in the band edge. The node is located in a distance of $600 \mathrm{~mm}$ from the front of the sheet.

Figure 9 illustrates the geometry of the tube and the paths of the band edge in y- and z-direction for all forming strategies. It shows that edge waves and bow occur for the forming strategy $2 \mathrm{R}$. Both $\mathrm{W}$-forming strategies show a goodnatured behavior regarding buckling, whereby strategy W1 also shows longitudinal bow, similar to the $2 \mathrm{R}$ strategy. In the evaluation area, the maximum deviation of the band edge of W2 in y-direction is $\Delta y=0.26 \mathrm{~mm}$ and $\Delta y=0.69 \mathrm{~mm}$ for W1.

2R:

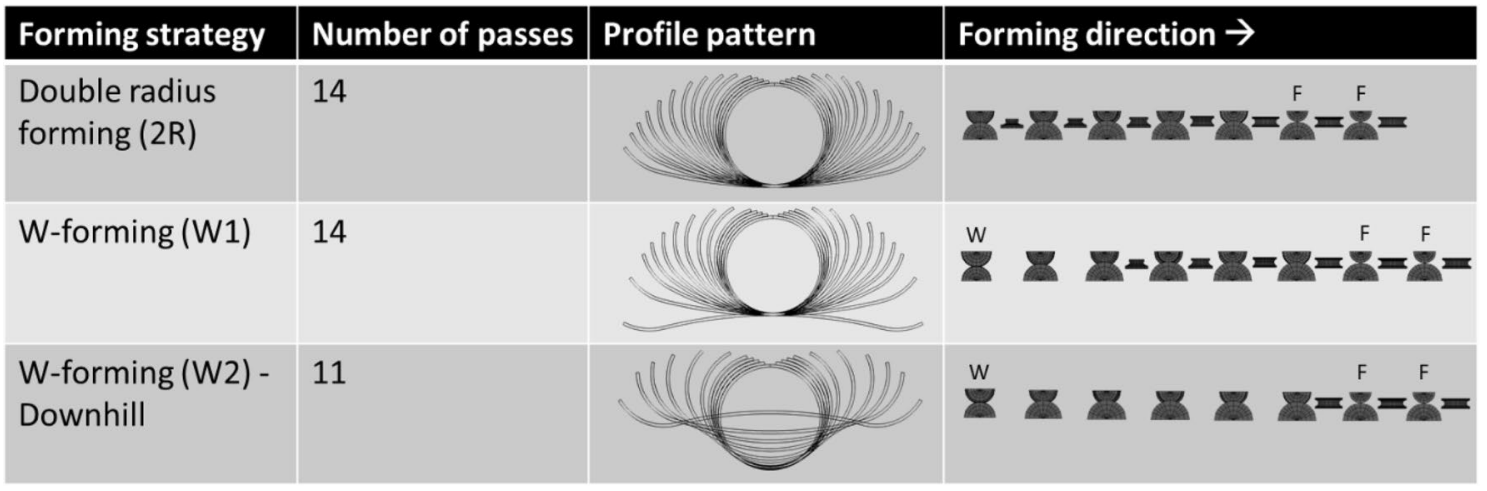

Fig. 7 Summary of roll forming strategies_*F: Fin-pass, *W: W-pass 
Table 3 Geometry of each forming pass in each forming strategy

\begin{tabular}{|c|c|c|c|c|c|c|c|c|c|c|c|c|}
\hline \multirow[t]{2}{*}{ Pass } & \multicolumn{4}{|l|}{$2 \mathrm{R}$} & \multicolumn{4}{|l|}{ W1 } & \multicolumn{4}{|l|}{ W2 } \\
\hline & $\mathrm{a}_{1}(\mathrm{~mm})$ & $\mathrm{r}_{1}(\mathrm{~mm})$ & $\mathrm{a}_{2}(\mathrm{~mm})$ & $\mathrm{r}_{2}(\mathrm{~mm})$ & $\mathrm{a}_{1}(\mathrm{~mm})$ & $\mathrm{r}_{1}(\mathrm{~mm})$ & $\mathrm{a}_{2}(\mathrm{~mm})$ & $\mathrm{r}_{2}(\mathrm{~mm})$ & $\mathrm{a}_{1}(\mathrm{~mm})$ & $\mathrm{r}_{1}(\mathrm{~mm})$ & $\mathrm{a}_{2}(\mathrm{~mm})$ & $\mathrm{r}_{2}(\mathrm{~mm})$ \\
\hline 1 & 22.3 & 30 & 61.7 & 250 & 22.3 & 30 & 61.7 & -250 & 34.4 & 26 & 49.6 & -200 \\
\hline 2 & 22.3 & 30 & 61.7 & 150 & 22.3 & 30 & 61.7 & 150 & 34.4 & 26 & 49.6 & 200 \\
\hline 3 & 23.6 & 28 & 60.4 & 119 & 23.6 & 28 & 60.4 & 119 & 34.4 & 26 & 49.6 & 100 \\
\hline 4 & 23.6 & 28 & 60.4 & 91 & 23.6 & 28 & 60.4 & 91 & 34.4 & 26 & 49.6 & 65 \\
\hline 5 & 25.7 & 26 & 58.3 & 75 & 25.7 & 26 & 58.3 & 75 & 34.4 & 26 & 49.6 & 45 \\
\hline 6 & 25.7 & 26 & 58.3 & 60 & 25.7 & 26 & 58.3 & 60 & 34.4 & 26 & 49.6 & 35 \\
\hline 7 & 28.1 & 26 & 55.9 & 50 & 28.1 & 26 & 55.9 & 50 & 34.4 & 26 & 49.6 & 30.8 \\
\hline 8 & 30.7 & 26 & 53.3 & 41 & 30.7 & 26 & 53.3 & 41 & 36.6 & 26 & 47.4 & 29.4 \\
\hline 9 & 30.7 & 26 & 53.3 & 35 & 30.7 & 26 & 53.3 & 35 & 38.4 & 26 & 45.6 & 28.3 \\
\hline 10 & 34.4 & 26 & 49.6 & 30.8 & 34.4 & 26 & 49.6 & 30.8 & 40.2 & 26 & 43.8 & 27.1 \\
\hline 11 & 36.6 & 26 & 47.4 & 29.4 & 36.6 & 26 & 47.4 & 29.4 & 42 & 26 & 42 & 26 \\
\hline 12 & 38.4 & 26 & 45.6 & 28.3 & 38.4 & 26 & 45.6 & 28.3 & & & & \\
\hline 13 & 40.2 & 26 & 43.8 & 27.1 & 40.2 & 26 & 43.8 & 27.1 & & & & \\
\hline 14 & 42 & 26 & 42 & 26 & 42 & 26 & 42 & 26 & & & & \\
\hline
\end{tabular}

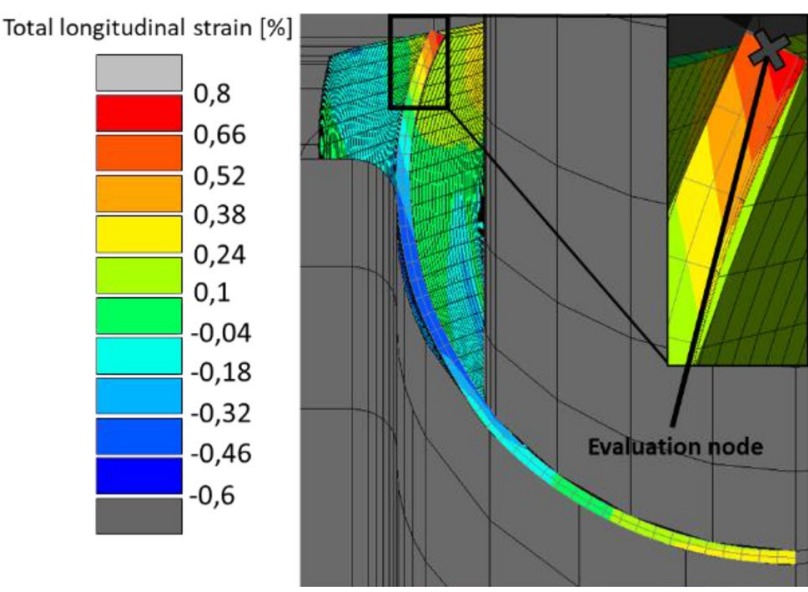

Fig. 8 Total longitudinal strain distribution in the band edge-cross section in the evaluation area

Figure 10 shows the longitudinal strain during the whole forming process. During 2R strategy, the side rolls in the second and fourth pass cause high longitudinal strain in the band edge. Maximum longitudinal strain during the process is $\varepsilon=0.0198$ for the $2 \mathrm{R}$ forming strategy. The fact that buckling (edge waves) and longitudinal bow occur for the double radius forming strategy requires another process design for the double radius strategy (e.g. more passes) or another forming strategy.

W1:

Characteristic in the first pass (W-forming pass) is the change from tension to compression in the band edge, which results from the $\mathrm{W}$-shape of the rolls. Plastic longitudinal strain is negative after the first pass (Fig. 11). Through the longitudinal compression of the band edge after pass one and the replacement of the side rolls in pass two through a breakdown pass, the longitudinal strain is reduced in pass two. The change from positive to negative strain allows higher bending angles in the next passes without exceeding the BLS. This results in a small reduction of the maximum total longitudinal strain from $\varepsilon=0.0198$ to $\varepsilon=0.0194$. For plastic strain, the maximum value is reduced from $\varepsilon=0.0128$ to $\varepsilon=0.0118$. Regarding final geometry, there is no significant difference between R2 and W1 forming strategy, except for the appearance of buckling.

\section{W2:}

The goal is to keep longitudinal strain as equal as possible in every stage of the process. Through the implementation of the down-hill forming, the efficiency of the process increases. The profile is lowered in each pass to reduce the elongation of the band edge and reduce the plastic elongation in the band edge. The down-hill forming enables to maximize the bending angle in the first pass without exceeding its critical value $[16,17]$. Nevertheless, the elongation of the band edge increases in the first pass compared to the other forming strategies.

Figure 10 shows that the total longitudinal strain in the band edge has peaks of approximately the same size over the entire process length. This results from the optimized flower pattern with enlargement of the unrolled length in the band edge area $a_{1}$ and the down-hill forming. For the W2-forming strategy, the maximum value of longitudinal strain of $\varepsilon=0.0155$ is low, compared to $\varepsilon=0.0198$ (2R) and $\varepsilon=0.0194$ (W1). After the first pass, longitudinal strain is nearly zero. From pass two to four, peak longitudinal strain increases from pass to pass, but it is still below the critical value for buckling. The highest longitudinal strain of $\varepsilon=0.0155$ occurs in the fin passes. The use of 


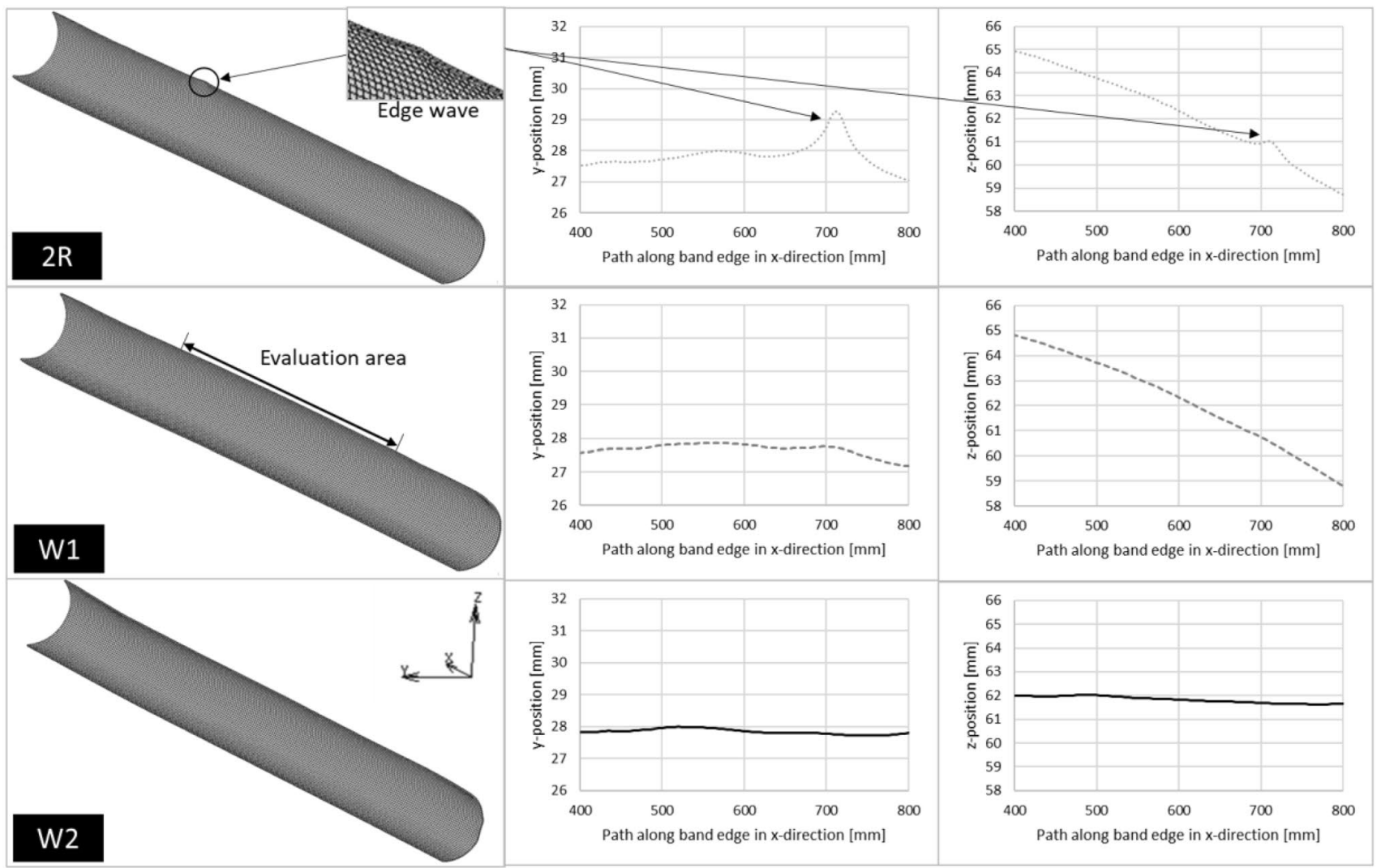

Fig. 9 Geometry of the tube with different forming strategies

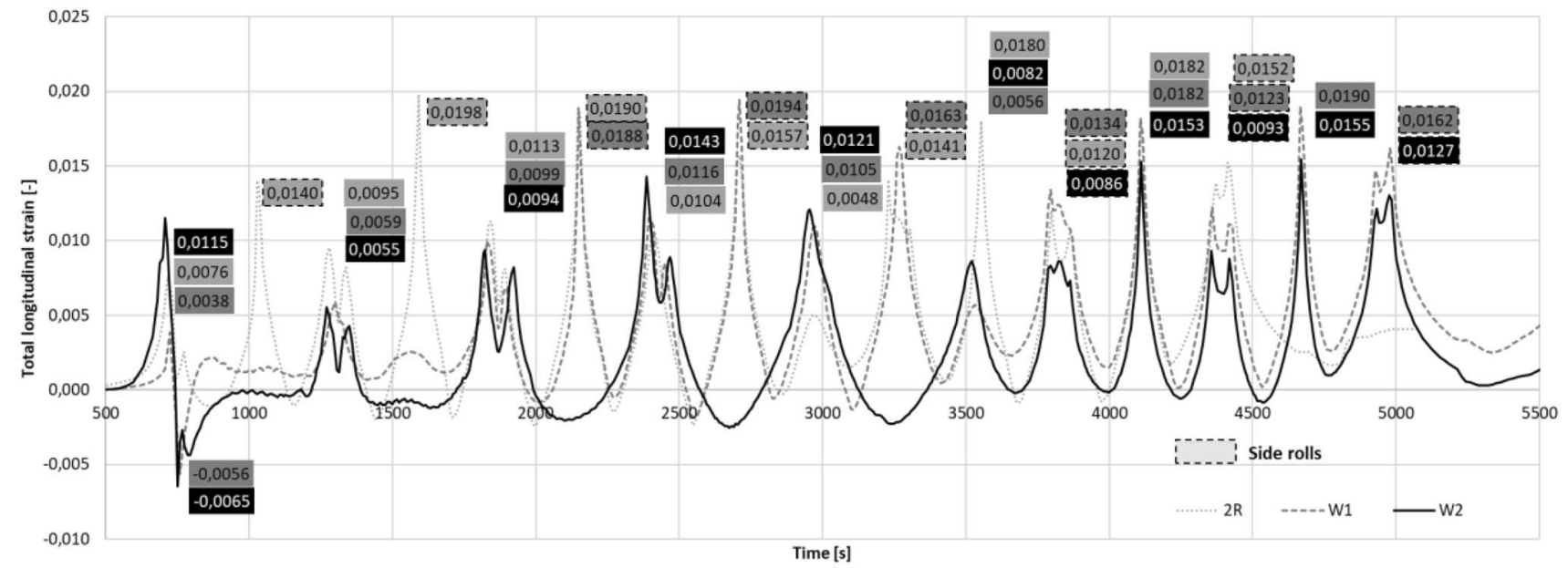

Fig. 10 Total longitudinal strain in length-direction at a sheet length of $600 \mathrm{~mm}$

breakdown passes as well as the optimized flower pattern and the downhill-strategy for forming strategy W2 lead to a reduction and homogenization of the longitudinal strain peaks in the band edge. The result of forming strategy W2 is good enough to weld a pipe in the subsequent process.

\subsubsection{Buckling limit strain}

There is a correlation between the maximum plastic longitudinal strain in the band edge and the appearance of buckling. Longitudinal plastic strain in the band edge during 


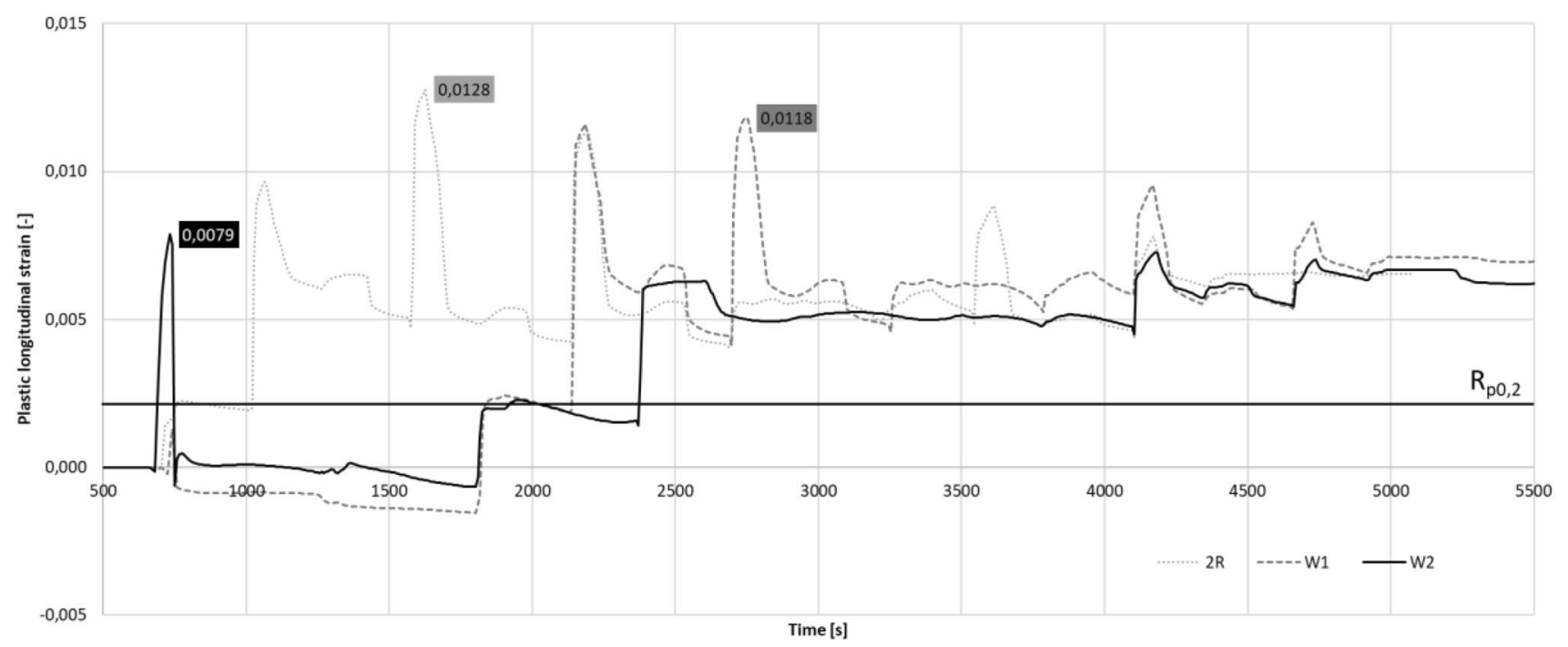

Fig. 11 Plastic longitudinal strain in length-direction at a sheet length of $600 \mathrm{~mm}$

the whole forming process for all forming strategies is illustrated in Fig. 11. The BLS is in the range of the maximum plastic longitudinal strains of the forming strategy $2 \mathrm{R}(\varepsilon=0.0128)$ and W1 $(\varepsilon=0.0118)$. Maximum longitudinal strain of $\varepsilon=0,0079$ of forming strategy W2 is clearly below BLS. Park [14] showed that BLS for roll forming an U-channel made of aluminum is $1.25 \%(\varepsilon=0.0125)$, which supports the result in this investigation.

The longitudinal strain distribution in the band edge is shown in Fig. 12. The peaks of the longitudinal strain fit to the areas of buckling in Fig. 9. All profiles show positive remaining longitudinal strain. The strain distribution of the $\mathrm{W}$-forming process routes is almost constant, which leads to the straight line of the band edge of the tube. With an average of $\varepsilon=0.0017$, the remaining strain for forming strategy W2 is the lowest of all forming strategies.

\subsubsection{Geometry and bending radius}

Apart from the profile quality with regard to buckling, there are no major differences in the profile geometry. All profiles have a deviation of approximately $y_{d e v}=28 \mathrm{~mm}$ in y-direction from the target geometry of the tube after springback as illustrated in Fig. 13. Another result shown is the radius of the profile along the circumference of the profile. The radius is determined from three adjacent nodes, what leads to high local amplitudes. Forming strategy $2 \mathrm{R}$ and W1 mainly differ in the edge area of the tube. This indicates that the W-forming does not have a major influence on the final geometry. The W2-forming strategy leads to a more uniform distribution of the bending radius with smaller peaks. Especially in the band edge area, the bending radius is smaller for the W2 strategy. This results from the smaller bending radius of the edge area in the first stages of the process. Although
Fig. 12 Total longitudinal strain distribution in the band edge after last pass and springback

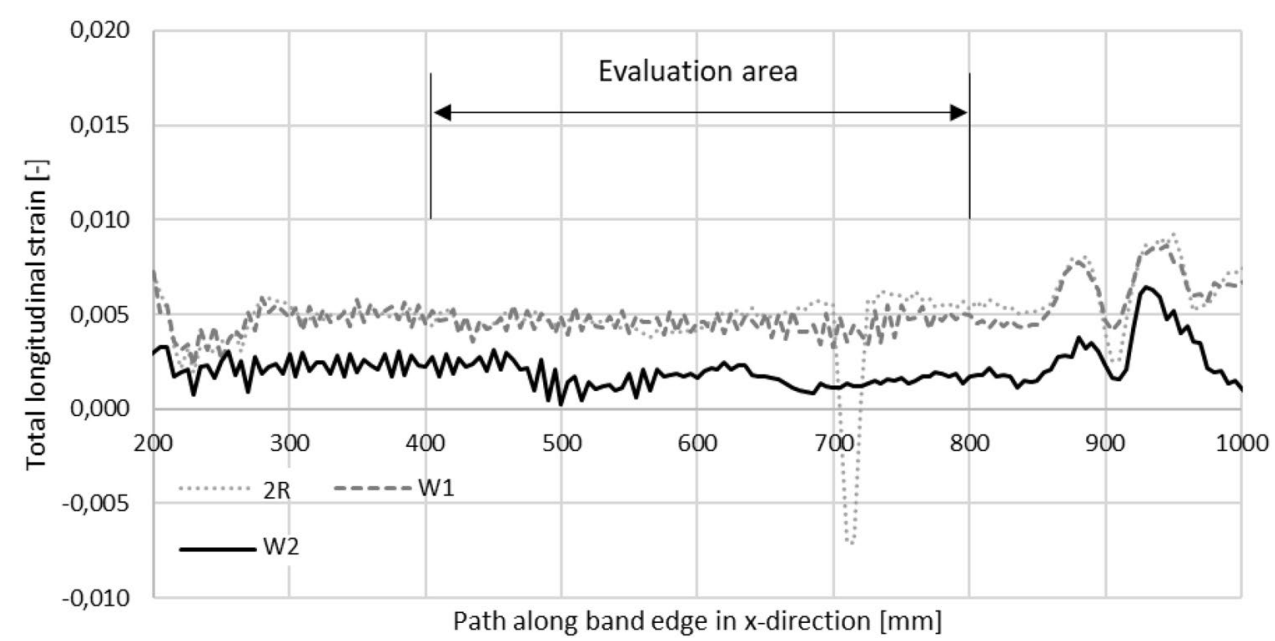



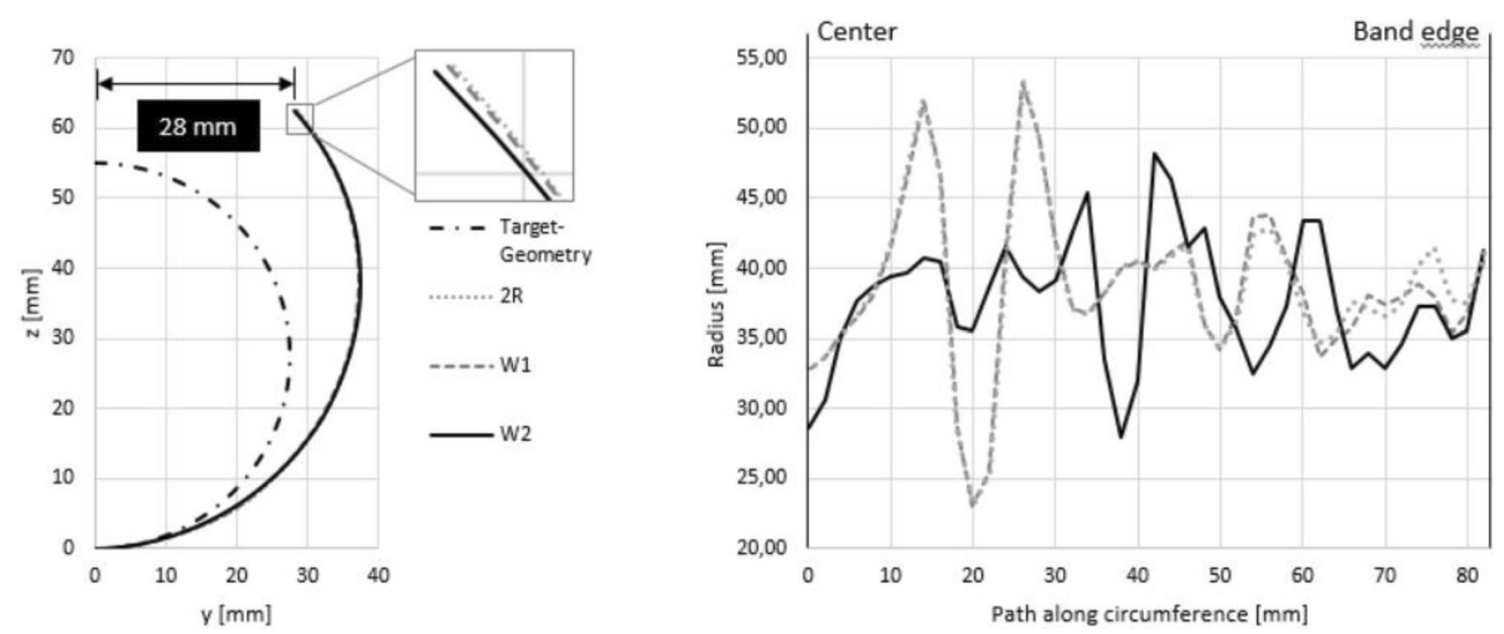

Fig. 13 Numerical results of the final cross section, compared with target shape and forming strategies

bending radii vary locally, the effect of the forming strategy on the global geometry of the tube is small. A locally reduced bending radius leads to an increased bending radius in another area in the tube, since the final pass of the forming process is always the same due to the fixed geometry of the final passes. With regard to springback, it is irrelevant which forming strategy is used to approach the final geometry. However, the forming strategy has a great influence on the band edge elongation.

\subsubsection{Welding of the tube}

The welding process follows the roll forming of the tube. Two different welding processes are in focus of the investigation: Laser beam welding and inductive high-frequency
(HF)-welding. Figure 14 shows the setup of the simulation for prediction of the welding forces. For the laser beam welding, only configurations with a gap on the top side are possible ( $\mathrm{H}$ and $\mathrm{A} 1$ ). The stiffness of the springs is $k=75.000 \frac{\mathrm{N}}{\mathrm{mm}}$ and the force is evaluated from the displacement of the rolls. The distance between the last forming pass and the welding pass is $l_{d}=400 \mathrm{~mm}$. The thermal impact of the welding process is not considered in the simulation.

The different arrangements of the rolls in the welding pass suggest that different force levels are required to compress the material into a closed tube during welding. Figure 15 shows, the forces, required in each roll. The total force for compressing the tube $F_{\text {total }}$ is the lowest for the horizontal rolls. For the HF-welding process, another arrangement of the rolls can be required since the high radius to thickness
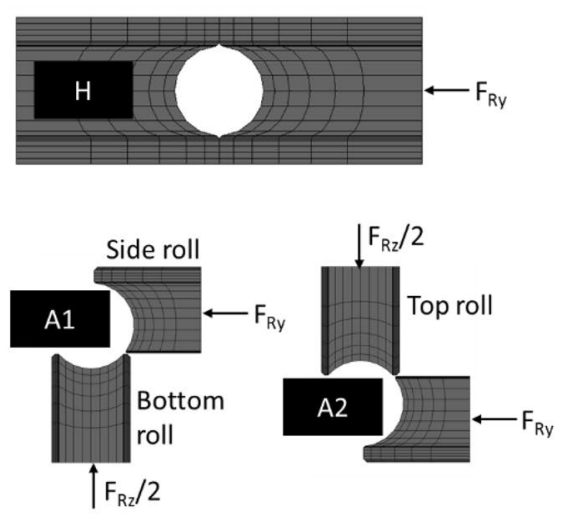
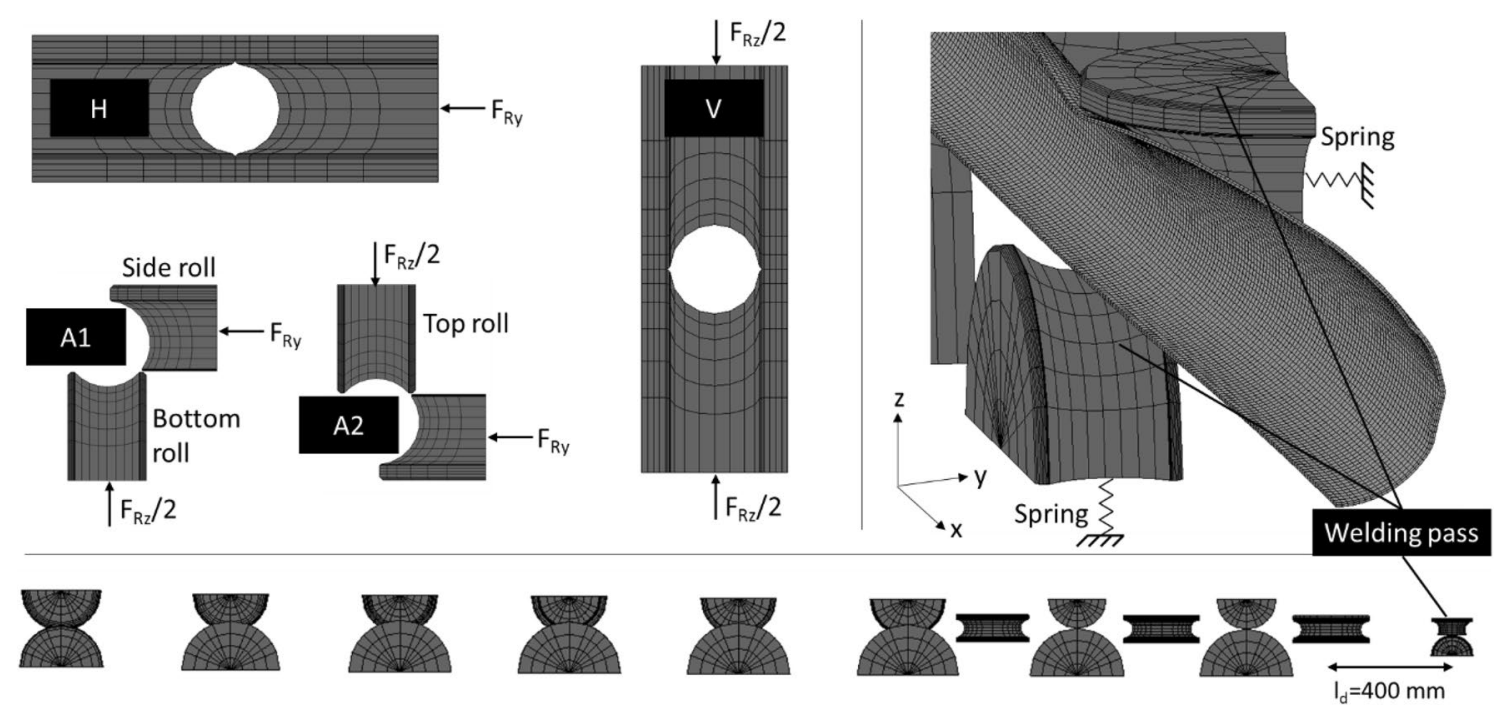

Fig. 14 Setup of the FE-model for prediction of the welding forces 
Fig. 15 Influence of the roll configuration on the welding force

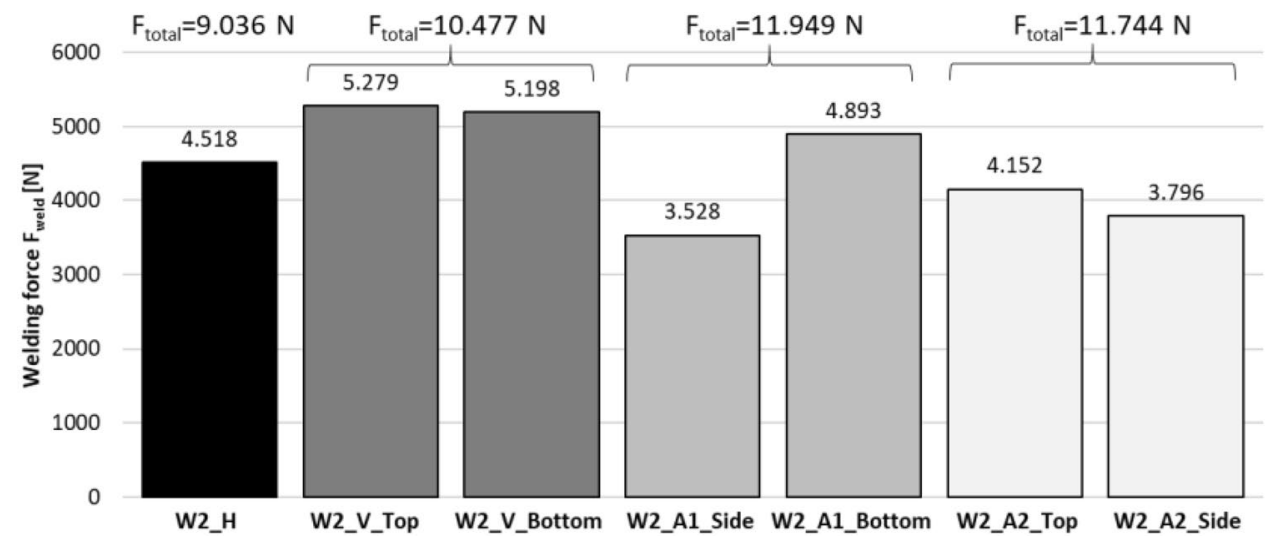

ratio $\mathrm{r} / \mathrm{t}$. According to Wright [30], the three roll arrangement A2 is appropriate for tubes $\frac{r}{t}>10$, which is in accordance with the results from the simulation. The forces of the side and vertical (top and bottom) rolls are more uniform for A2 than for A1. The more uniform distribution of force ensures a smoother contact pressure. In summary, the best result for laser welding could be expected with strategy $\mathrm{H}$ and for HF welding with strategy A2.

The dependence of the forming strategy is investigated for the welding roll arrangement H. For the W2-strategy the required force $F_{\text {total }}$ is $7 \%$ higher than for the $2 \mathrm{R}$ and the W1 strategy. This results from the different distribution of the bending radii of the forming strategies. In the transition area from $a_{1}$ to $a_{2}$, the springback of strategy W2 is larger than for $2 \mathrm{R}$ and $\mathrm{W} 1$, which can create the difference. Nevertheless, the difference is too small to consider the force as a decisive additional design criterion for the roll forming process.

\subsubsection{Recommendations for the choice of the forming strategy}

- W-forming is recommended. The compression of the band edge after pass 1 leads to a lower plastic elongation of the band edge and thus to a reduced buckling tendency of the band edge.

- The use of a downhill strategy reduces the elongation of the band edge, especially in the first passes.

- Appropriate roll design regarding the use of the type of rolls. The use of side rolls is not recommended in the first passes as they cause a high elongation of the band edge.

- The combination of forming the target radius in the band edge area (high elongation of the band edge) in combination with the downhill strategy (reduced elongation of the band edge) leads to high efficiency thanks to the large forming operation at the beginning of the process.

- For a high process efficiency, it is recommended to keep the maximum longitudinal strain as equal as possible in each pass.

\section{Experimental results of roll forming strategy W2}

Roll forming experiments were conducted on a roll forming line type P3.200 by Dreistern, as seen in Fig. 16. For the experiments, the tools of roll forming strategy W2 are installed at the roll forming line. Feeding speed in the experiments is $v=1 \frac{\mathrm{m}}{\mathrm{min}}$ and the lubrication is a medium viscous oil directly on the aluminum sheet. The cross sections of the profiles after pass 1, 2, 3 and 11 were measured with the Bytewise 360 laser line measurement system after springback.

The measurement of the profiles as well as the simulation results are shown after springback in Fig. 17. Due to the poor process parameters regarding springback, high springback occurs in the process.

As in the numerical simulation buckling does not occur in the experiments (Fig. 17-Pass 11), and springback is slightly bigger in experiments. Deviations of the band edge position from numerical simulation to the experimental

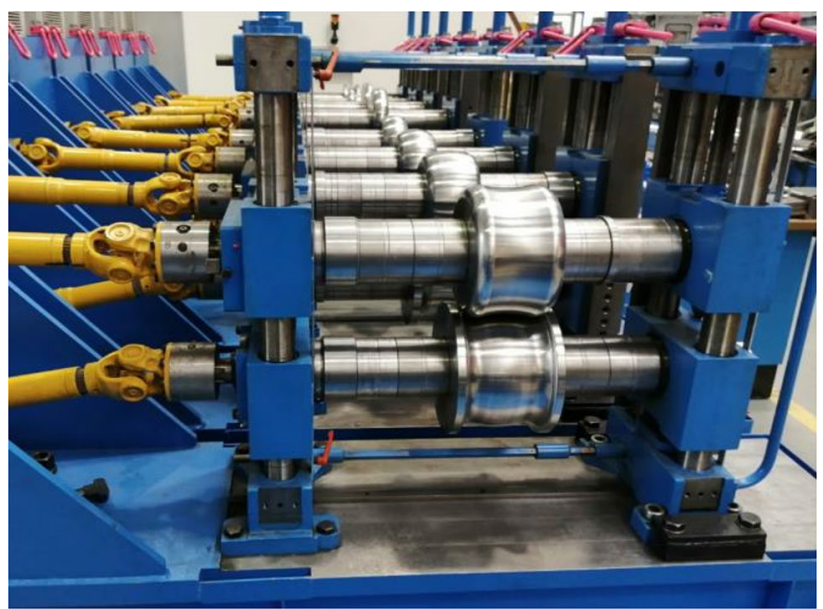

Fig. 16 Experimental setup for the roll forming experiments-W2 

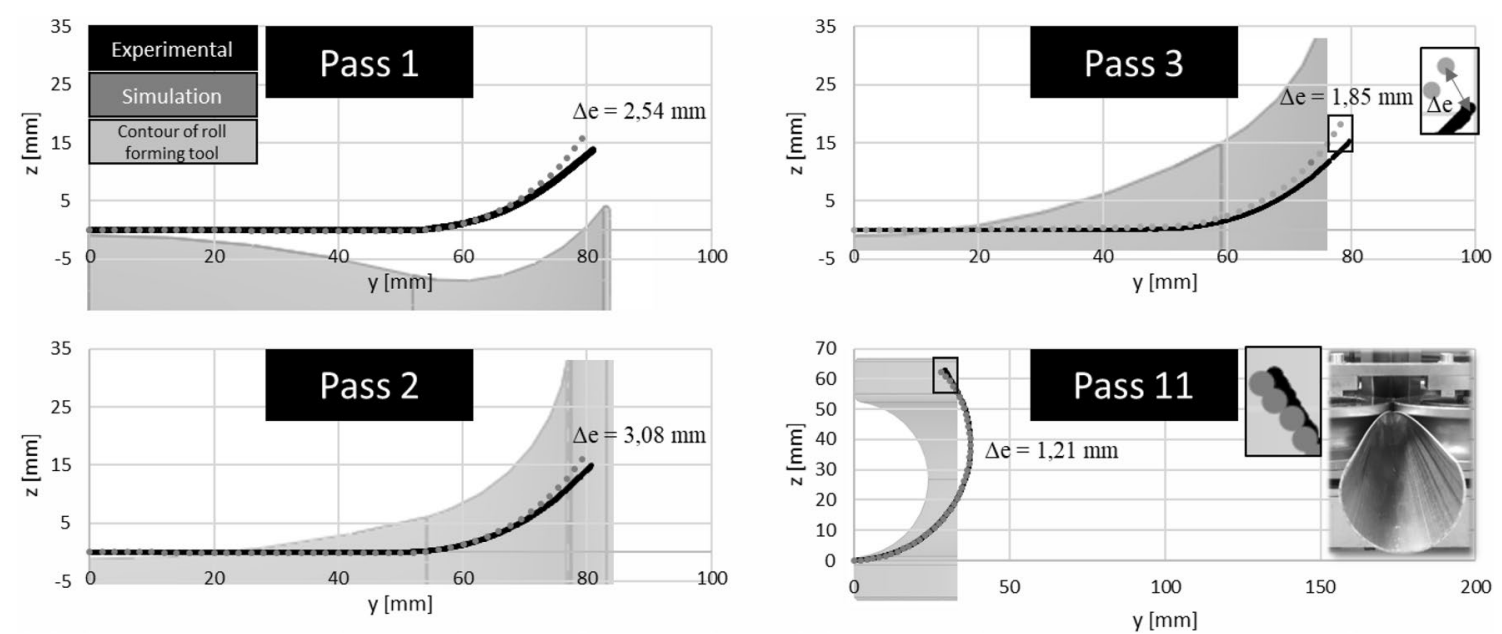

Fig. 17 Numerical and experimental results of the roll forming process-pass 1, 2, 3 and 11-W2

results are small. According to the described modelling strategy in chapter 3.1, the level of detail of the FE-model is good enough to meet the requirements for investigating the buckling and springback phenomena in the simulation. Taking into account the compliant rolls in the simulation with a stiffness of $k=75.000 \frac{\mathrm{N}}{\mathrm{mm}}$ for the upper- and the side rolls, the result is improved by $\Delta e=0.31 \mathrm{~mm}$ for the final geometry in pass 11 .

The negative bending in the first pass of the W-forming strategies is changed into positive bending in the further passes, as illustrated in Fig. 18. Isotropic hardening mechanisms in FE-models are not appropriate for these bending changes, if the extent of alternating bending is too high. According to [13, 31] 32 combined hardening models, which also consider the kinematic hardening part, are more accurate for springback modelling.

Plastic strain distribution on top of the sheet in pass 1 is illustrated in Fig. 19. It shows the greatest plastic deformation due to negative bending in the highlighted area. With regard to the von Mises' Criterion, the yield strength of $R_{p 0,2}=505 M P a$ is exceeded in the passes 1 and 3. Isotropic hardening law leads to a uniform increase of the yield surface. In pass 1 , there is tensile stress $\left(\sigma_{\mathrm{y}}=431 \mathrm{MPa}\right)$ on the upper side of the sheet with the largest plastic deformation
Fig. 18 Bending stress $\sigma_{\mathrm{y}}$ in pass 1, 2 and 3-W2

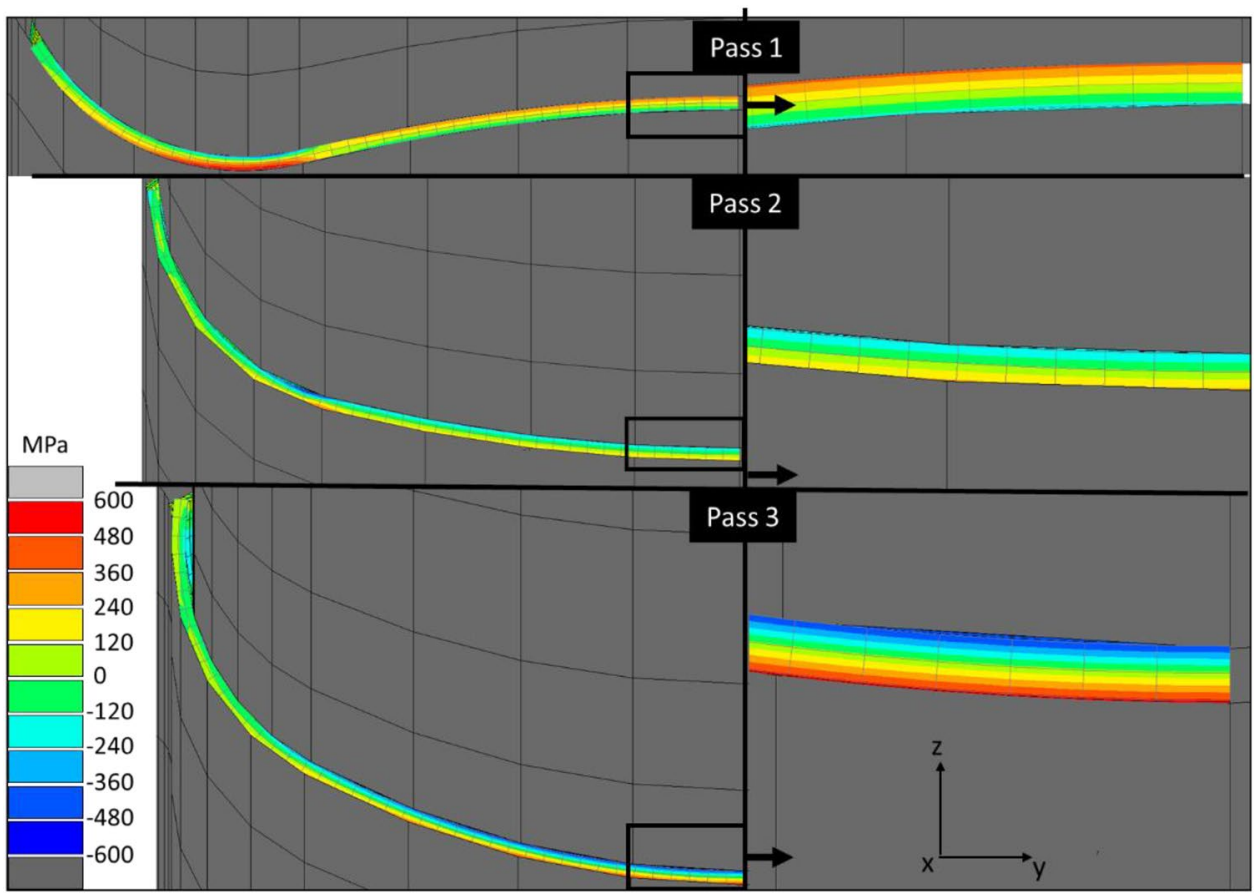




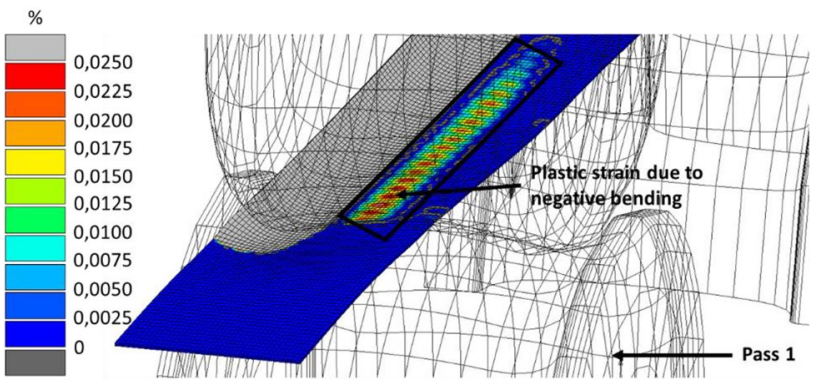

Fig. 19 Plastic strain distribution in pass $1-\mathrm{W} 2$

(Fig. 19), while in pass 3 the tensile stress changes to compressive stress $\left(\sigma_{\mathrm{y}}=-450 \mathrm{MPa}\right)$. The change of tensile stress to compressive stress is shown in Fig. 20.

Furthermore, there is an effect of plastic strain on Young's modulus. Yamaguchi and Yu showed that Young's modulus decreases with increasing plastic strain [33, 34]. As the Young's modulus decreases, the springback becomes larger in the numerical simulation. Taking the effects of compliant rolls, combined hardening and dependency of Young's modulus from plastic strain into account, a more accurate prediction of springback could be expected. Nevertheless, referring to the modeling strategy, the simplifications are reasonable for the evaluation of buckling and final geometry in the design phase.

\section{Conclusion and summary}

In this paper, roll forming of a high strength aluminum tube is investigated. Due to the difficult determination of the design parameters, roll forming of high strength aluminum is a challenge. Conventional roll forming strategies quickly reach their limits when forming aluminum or high strength steels. To form a tube out of high-strength aluminum alloys such as AA7075, a W-forming strategy is recommended. Another positive influence is the application of a down-hill strategy. The investigations have shown that an efficient roll forming production line for high strength aluminum tubes can be set up even with a small number of forming passes. The $\mathrm{W}$-forming strategies showed a good behavior with regard to buckling, compared to the double radius forming strategy. Forming strategy W2 combines the advantages of few passes with a good final part geometry thanks to detailed process design. The numerical investigation and the following experiments demonstrated the feasibility of roll forming a high-strength aluminum tube. It is shown that conventional design methods are also valid for high-strength materials.

A further result of the numerical investigation is that the design of the tools should not be based on longitudinal strain in the band edge alone. For a first estimation, the elongation of the band edge is a valid factor, but for an exact process design a numerical simulation should always be performed. In addition, BLS is material dependent, which makes an analytical calculation even more difficult.

Regarding the springback angle, the experimental investigations show little deviations from the FE-model. The reasons for this are the simplified material model, which does not consider combined hardening effects, the influence of the smaller modulus of elasticity after plastic deformation and compliance of the forming stand. Nevertheless, the simplified FE-model provides sufficiently accurate results regarding buckling and geometry of the tube.

Acknowledgements The authors gratefully acknowledge financial support from the Hessen State Ministry for Higher Education, Research and the Arts- Initiative for the Development of Scientific and Economic Excellence (LOEWE) for the Project ALLEGRO (Subproject A1)

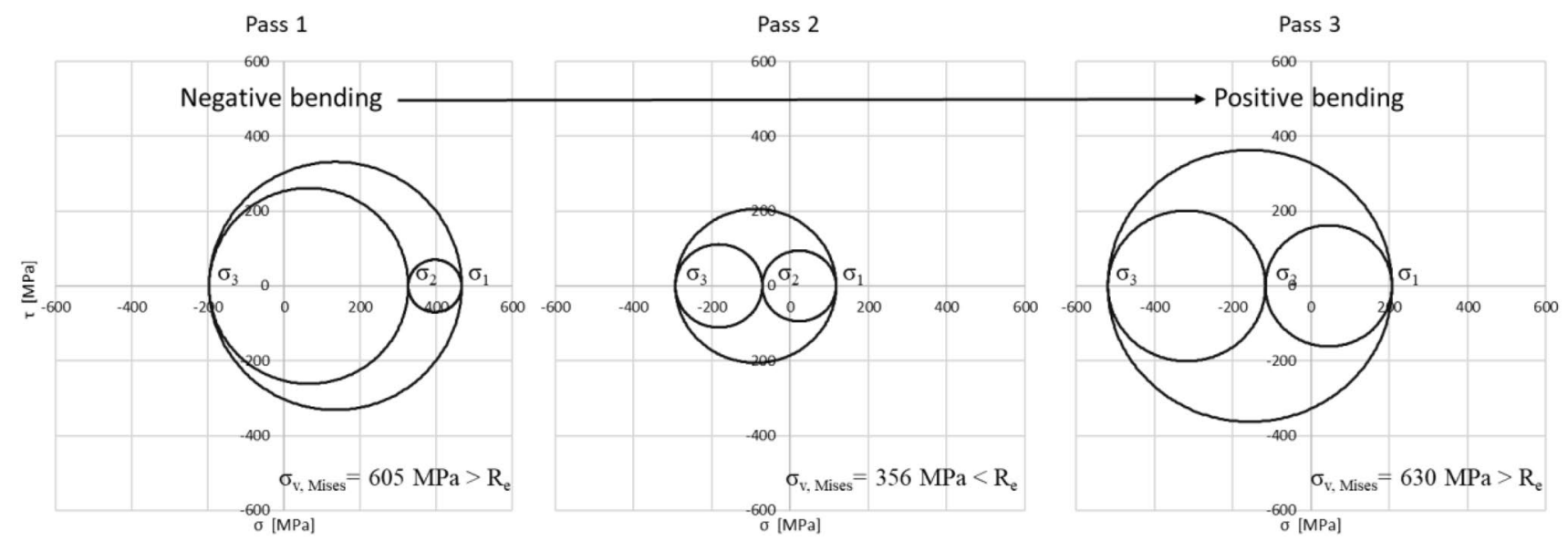

Fig. 20 Mohr's circle for the 3D stress distribution on the upper side of the sheet-W2 
Funding Open Access funding enabled and organized by Projekt DEAL. Hessen State Ministry for Higher Education, Research and the Arts-Initiative for the Development of Scientific and Economic Excellence (LOEWE).

Availability of data The datasets generated during and/or analyzed during the current study are available from the corresponding author on reasonable request.

\section{Declarations}

Conflict of interest The author declares that they have no competing interest.

Open Access This article is licensed under a Creative Commons Attribution 4.0 International License, which permits use, sharing, adaptation, distribution and reproduction in any medium or format, as long as you give appropriate credit to the original author(s) and the source, provide a link to the Creative Commons licence, and indicate if changes were made. The images or other third party material in this article are included in the article's Creative Commons licence, unless indicated otherwise in a credit line to the material. If material is not included in the article's Creative Commons licence and your intended use is not permitted by statutory regulation or exceeds the permitted use, you will need to obtain permission directly from the copyright holder. To view a copy of this licence, visit http://creativecommons.org/licenses/by/4.0/.

\section{References}

1. Suckow T, Günzel J, Schell L, Sellner E, Dagnew J, Groche $P$ (2019) Temperatureinfluss in der Aluminium-Blechumformung-Rückfederungsverhalten und Prozessgrenzen beim Gesenkbiegen von EN AW-6082 und EN AW-7075. Wt Werkstattstechnik online 10:733-739

2. Tisza M, Lukacs $Z$ (2017) High strength aluminum alloys in car manufacturing. Arch Mater Sci Eng 2:68-74. https://doi.org/10. 5604/01.3001.0010.8041

3. DIN 8586 (2003) Fertigungsverfahren Biegeumformen-Einordnung, Unterteilung, Begriffe. Beuth Verlag, Berlin

4. Lindgren M (2005) Finite element model of roll forming of a U-channel profile. In: International conference on technology of plasticity, ICTP, Verona

5. Abeyrathna B, Rolfe B, Weiss M (2017) The effect of process and geometric parameters on longitudinal edge strain and product defects in cold roll forming. Int J Adv Manuf Technol 92:743-754. https://doi.org/10.1007/s00170-017-0164-x

6. Farzin M, Salmani M, Shameli E (2002) Determination of buckling limit of strain in cold roll forming by the finite element analysis. J Mater Process Technol 125-126:626-632. https:// doi.org/10.1016/S0924-0136(02)00357-6

7. Park HS, Anh TV (2012) Development of evolutionary method for optimizing a roll forming process of aluminum parts. J Manuf Sci Eng. doi 10(1115/1):4005804

8. Bui QV, Ponthot JP (2008) Numerical simulation of cold rollforming processes. J Mater Process Technol 202:275-282. https://doi.org/10.1016/j.jmatprotec.2007.08.073

9. Kiuchi M, Abe K, Onodera R (1995) Computerized Numerical Simulation of Roll-Forming Process. CIRP 44:239-242. https:// doi.org/10.1016/S0007-8506(07)62316-6

10. Halmos GT (2006) Roll forming handbook. Taylor \& Francis, London
11. Groche P, Beiter P, Henkelmann M (2008) Prediction and inline compensation of springback in roll forming of high and ultrahigh strength steels. Product Eng 2:401-407. https://doi.org/10. 1007/s11740-008-0131-3

12. Zou T, Zhou N, Peng Y, Tang D, Li D (2016) Numerical simulation of the roll forming process of aluminum folded micro-channel tube. J Phys Conf Ser. https://doi.org/10.1088/1742-6596/ 734/3/032016

13. Lee S, Lee J, Song J, Park J, Choi S, Noh W, Kim G (2018) Fracture simulation of cold roll forming process for aluminium 7075-T6 automotive bumper beam using GISSMO damage model. Proc Manuf 15:751-758. https://doi.org/10.1016/j. promfg.2018.07.314

14. Park HS, Tran VA (2010) Finite element analysis of roll forming process of aluminum automotive component. Int Forum Strateg Technol Proc 2010:5-9. https://doi.org/10.1109/IFOST.2010. 5667921

15. Groche P, Breitenbach G (2008) Roll forming strategies for welded tubes. Steel research int. 79:40-46. https://doi.org/10. 1002/srin.200806314

16. Wen B, Pick RJ (1994) Modelling of skelp edge instabilities in the roll forming of ERW pipe. J Mater Process Technol 41:425446. https://doi.org/10.1016/0924-0136(94)90006-X

17. Salmani M, Moslemi H, Hartley P, Khademizadeh H (2006) Localized edge buckling in cold roll-forming of circular tube section. J Mater Process Technol 177:617-620. https://doi.org/ 10.1016/j.jmatprotec.2006.03.201

18. Breitenbach G (2008) Methode zur Analyse, Bewertung und Optimierung der Prozesskette Profilieren längsnahtgeschweißter Rohre für das Innenhochdruck-Umformen. Dissertation, Institute for Production Engineering and Forming Machines, TU Darmstadt

19. Jiang J, Li D, Yinghong P, Jianxin L (2009) Research on strip deformation in the cage roll-forming process of ERW round pipes. J Mater Process Technol 209:4850-4856. https://doi.org/ 10.1016/j.jmatprotec.2009.01.011

20. Volk W, Groche P, Brosius A, Ghiotti A, Kinsey BL, Liewald M, Madej L, Min J, Yanagimoto J (2019) Models and modelling for process limits in metal forming. CIRP Ann 68:775-798. https:// doi.org/10.1016/j.cirp.2019.05.007

21. Selvik JT, Abrahamsen EB (2017) On the meaning of accuracy and precision in a risk analysis context. Proc Inst Mech Eng J Mater Des Appl 231(2):91-100. https://doi.org/10.1177/17480 06X16686897

22. DIN EN ISO 6892:1 (2020) Metallische Werkstoffe-Zugversuch-Teil 1: Prüfverfahren bei Raumtemperatur. Beuth Verlag, Berlin

23. Damm K (1989) Ermittlung von Längsformänderungen beim Walzprofilieren von Standardprofilen auf einer mehrgerüstigen Anlage. Dissertation, Institute for Production Engineering and Forming Machines, TU Darmstadt

24. Groche P, Mueller C, Traub T, Butterweck K (2013) Experimental and numerical determination of roll forming loads. Steel Res Int. 85:112-122. https://doi.org/10.1002/srin.201300190

25. Mueller C, Gu X, Baeumer L, Groche P (2014) Influence of friction on the loads in a roll forming simulation with compliant rolls. Key Eng Mater 611-612:436-443. https://doi.org/10. 4028/www.scientific.net/KEM.611-612.436

26. Mueller C (2014) Numerische Abbildung und Validierung von Beanspruchungsgrößen in Rollprofilierprozessen. Dissertation, Institute for Production Engineering and Forming Machines, TU Darmstadt

27. Moneke M, Groche P (2017) Counter measures to effectively reduce end flare. ESAFORM Conf Mater Form Proc. https://doi. org/10.1063/1.5007963 
28. Goertan M, Vucic D, Groche P, Livatyali H (2009) Roll forming of branched profiles. J Mater Process Technol 209:5837-5844. https://doi.org/10.1016/j.jmatprotec.2009.07.004

29. Mahajan P, Abrass A, Groche P (2018) FE simulation of roll forming of a complex profile with the aid of steady state properties. Steel Res int. https://doi.org/10.1002/srin.201700350

30. Wright J (1997) Principles of high frequency induction tube welding. Electronic heating equipment. Sumner Inc., Washington

31. Dongjuan Z, Zhenshan C, Xueyu R, Yuqiang L (2006) Sheet springback prediction based on non-linear combined hardening rule and Barlat89's yielding function. Comput Mater Sci 38:256-262. https://doi.org/10.1016/j.commatsci.2006.02.007

32. Lee J, Lee J, Lee M, Barlat F (2012) An application of homogeneous anisotropic hardening to springback prediction in pre-strained U-draw/bending. Int J Solids Struct 49:3562-3572. https://doi.org/10.1016/j.ijsolstr.2012.03.042

33. Yamaguchi K, Adachi H, Takakura N (1998) Effects of plastic strain and strain path on young's modulus of sheet metals. Metals Mater 4:420-425. https://doi.org/10.1007/BF03187802

34. Yu H (2009) Variation of elastic modulus during plastic deformation and its influence on springback. Mater Des 30:846-850. https://doi.org/10.1016/j.matdes.2008.05.064

Publisher's Note Springer Nature remains neutral with regard to jurisdictional claims in published maps and institutional affiliations. 